\title{
High level of Brazilian men's volleyball: characterization and difference of predictive factors of back row attack
}

\author{
Gustavo De Conti Teixeira Costa $1^{*}$, Henrique de Oliveira Castro ${ }^{2}$, Auro Barreiros Freire 3 , \\ Breno Ferreira Evangelista ${ }^{4}$, Gustavo Ferreira Pedrosa ${ }^{5,6}$, Herbert Ugrinowitsch ${ }^{5}$, Gibson \\ Moreira Praça ${ }^{5}$
}

\begin{abstract}
This study aimed to identify the predictive factors of attacks, performed from positions 1 and 6 according to the effect of reception in high level Brazilian male volleyball and to find the predictive factors that differentiate the game practiced from these positions. The sample consisted in the observation of 142 games of the Brazilian Men's Super League, totalling 2969 actions of reception, setting and attack from positions 1 and 6 . The significance value adopted was $5 \%(\mathrm{p} \leq 0.05)$. The analysis of the predictive factors of the game performed by the attacker of position 1 showed greater chances to score after an excellent (odds ratio adjusted - ORA $=1.48$ ) and moderate effect of reception (ORA $=1.31$ ), the second attack tempo $($ ORA $=1.32)$, the powerful attack in parallel $($ ORA $=1.91)$ and in diagonal $($ ORA $=3.44)$. The attacker of position 6 showed higher chances of scoring after a high effect of reception $($ ORA $=3.39)$ and powerful attack in the parallel $(\mathrm{ORA}=1.53)$. In conclusion, regardless the effect of reception, the use of the back-row attackers is recommended to increase the uncertainty on the opposing team and the chances to score.

Keywords: Game analysis, Team preparation, Sports team
\end{abstract}

\section{INTRODUCTION}

The studies on game analysis have the premise of optimizing team preparation processes, as well as assisting in the development of concepts and strategies that increase team effectiveness during training and games (Fernandez-Navarro, Fradua, Zubillaga, Ford, \& McRobert, 2016; Gómez, Silva, Lorenzo, Kreivyte, \& Sampaio, 2016;). In volleyball, it may be observed studies that opted for descriptive, correlational and predictive analyses (Mesquita, Palao, Marcelino, \& Afonso, 2013; Silva, Marcelino, Lacerda, \& João , 2016a), however, only the predictive studies allowed to understand the interference of the game procedures in relation to the dependent variable in volleyball (Mesquita et al., 2013).
The analysis of the factors that influence the final result of the game shows that, in male volleyball, the effect of the attack is the factor that presents the highest predictive power in the victory of the set (Drikos \& Vagenas, 2011), as well as the attack after the reception (Marelic, Zufar, \& Omrcen, 2004) and the blocking (Rocha \& Barbanti, 2006). In this context, it is noticed that the performance in the attack modulates the final result in the set and in the team performance. The analysis of the predictive factors of the effect of the attack are related to the effect of the reception (Afonso, Esteves, Araújo, Thomas, \& Mesquita, 2012; João \& Pires, 2015, Silva, Lacerda, \& João, 2014b), the attack tempo (Nikos \& Elissavet, 2011) and type of attack (Costa, Ferreira, Junqueira, \& Afonso, 2011). Moreover, other studies that analysed the

\footnotetext{
Manuscript received at June 23 ${ }^{\text {rd }} 2017$; Accepted at September $28^{\text {th }} 2017$

${ }^{1}$ Universidade Federal de Goiás, Goiânia, Brasil

${ }^{2}$ Centro Universitário Estácio de Brasília, Brasília, Brasil

${ }^{3}$ Centro Universitário Estácio de Belo Horizonte, Belo Horizonte, Brasil

${ }^{4}$ Sesi, Itaúna, Brasil

${ }^{5}$ Universidade Federal de Minas Gerais, Belo Horizonte, Brasil

${ }^{6}$ Centro de Instrução e Adaptação da Aeronáutica, Belo Horizonte, Brasil

* Corresponding author. Av. Esperança, s/n - Chácaras de Recreio Samambaia, Goiânia - GO, 74690-900, Brasil Email:conti02@hotmail.com
} 
offensive structuring showed that there are differences in the distribution of the game according to the position of the setter (Silva et al., 2013, 2014a), the availability of the middle hitter (Mesquita et al., 2013), the number of available attackers and the athlete who performed the reception (Afonso et al., 2012).

Although researches show that in male volleyball the high effect of reception (Asterios, Kostantinos, Athanasios, \& Dimitrios, 2009; Zetou, Tsigilis, Moustakidis, \& Komninakidou, 2007;), faster attack tempo (Palao, Santos, \& Ureña, 2007) and powerful attacks (Costa et al., 2011; Costa, Barbosa, Freire, Matias, \& Greco, 2014) are predictive factors of the point of attack, it was not observed in the literature the analysis of these factors according to the position of the attack. In addition, the studies did not distinguish the effect of the attack according to the effect of reception, which may entail a decontextualized game analysis, since the effect of reception limits the options of setting and the construction of the attack (Costa et al. 2016b). In this way, it is necessary to analyse the attack situations that present similar initial contexts, allowing finding the predictive factors of the attack for each specific game scenario. Furthermore, considering the emerging patterns of the game, it has been noticed the claim of the offensive system to be composed of 4 attackers (Silva, Sattler, Lacerda, \& João, 2016b), being essential the back row attack, specifically from zone 1 and 6 (Costa et al., 2016a). Knowing that the recent studies analysed, majority, the attack from the positions 2, 3 and 4 (Millán-Sanchez, Rábago, Hernández, Marzo, \& Ureña, 2015), the present study has as objective to identify the predictive factors of the attacks performed behind the 3 meters line, namely positions 1 and 6 , according to the effect of reception in high level male Brazilian volleyball, as well as, to find the predictive factors that differ the type of game practiced from these positions.

\section{METHODS:}

\section{Sample:}

The sample consisted of the observation of 142 games of the Brazilian Men's Volleyball
Super League, being analysed all the 12 participating teams of the season 2014-2015, totalling 2969 actions of reception, setting and attack from the positions 1 and 6 , distinguishing itself in 2045 attacks of positions 1 and 924 of position 6. Position 5 was not considered because there was no attack from this zone. This is explained by the fact that it corresponds to the position of permanence of the libero in the observed teams. The failure receptions were excluded from the sample, since they did not allow the continuation of the action and subsequent accomplishment of the attack. The local ethics committee of the Federal University of Minas Gerais, Brazil, approved this study, which complies with international standards.

\section{Instruments}

\section{Effect of Reception}

To evaluate the effect of reception, the instrument proposed by Maia and Mesquita (2006) was adapted. The following rating scale was used:

- Reception of low effect (C): reception that did not allow the organization of the attack, evidencing the location of the distribution of the attack.

- Reception of moderate effect (B): Reception that allowed the organized attack, although not all the attackers were available for the attack. More specifically, reduced the chances of rapid attacks.

- Reception of excellent effect (A): reception that allowed an organized attack with all the attackers available for the attack.

\section{Attack tempo}

The categories that make up this dimension were adapted from Afonso, Mesquita, Marcelino, and Silva (2010) and the following scale was used:

- $1^{\text {st }}$ attack tempo: the attacker jumped during or immediately after the setting, and a step may occur after the setting;

- $2^{\text {nd }}$ attack tempo: the attacker made two or three steps after the setting;

- 3rd attack tempo: the attacker waited for the ball to reach the peak of the ascending trajectory and only then began the attack steps. 


\section{Types of attack}

It corresponds to the technical criteria related to the attack. To analyse the type of attack, an adaptation of the instrument proposed by Costa et al. (2011, 2016b), was used. The attacks that hit the blocking with power were grouped to strong attacks in parallel or diagonal, according to the trajectory of the ball, while the soft attacks that hit the blocking were grouped to the category off-speed attack. In this sense, the types of attack were divided into the following categories:

- Strong Attack in Parallel (SAP): Attack performed in position 1 with downward trajectory, parallel to the side-line with imposition of maximum power or attack performed in position 6 with downward trajectory, directed to zone 6 of the opposing team with imposition of maximum power.

- Strong Attack in Diagonal (SAD): Attack performed straight down, diagonally to the sideline with maximum power.

- Off-speed Attack (OSA): Attack performed against the ball with less force.

\section{Effect of the attack}

We used an adaptation of the instruments proposed by Eom and Schutz (1992) and Marcelino, Mesquita, and Sampaio (2011), obtaining the following categories:

- Error: The attacker failed due to 1) the opponent's block, resulting in an opponent's point; 2) the ball hit the net; 3) the ball fallen out of line; 4) violation on the rules.

- Continuity: the attack action did not result in a terminal action and allowed the opponent counterattack.

- Point: the attack resulted in a direct point as the ball touched the opponent's court or was deflected off the court by the blocking.

\section{Procedures}

All games were recorded from top perspective, about 7-9 meters behind the backcourt line and a camera was positioned approximately 3 meters above ground level for better viewing of video scenes. A Sony camera with 1080p HD definition and a frequency rate of $60 \mathrm{~Hz}$ was used. Observers were physical education professionals and volleyball statisticians with at least 5 years of experience in this specific function. For the calculation of reliability, $20 \%$ of the actions were re-analysed, exceeding the reference value of $10 \%$ (Tabachnick \& Fidell, 2013). The Cohen values for inter and intra-observer reliability, respectively, were: reception effect $=0.98$ and 0.96 ; attack tempo $=0.90$ and 0.92 ; type of attack $=1.00$ and 1.00; attack effect $=1.00$ and 1.00. In this sense, the reliability values are above the reference value which is 0.75 (Fleiss, Levin, \& Paik, 2003).

\section{Statistical Procedures}

For descriptive statistical analysis, SPSS 20.0 for Windows was used. Subsequently, the multinomial logistic analysis was performed (odds ratio adjusted - ORA), observing the relation of the independent variables with the dependent variable one by one. For characterization of the game practiced by the attackers of positions 1 and 6 , it was considered as dependent variable the effect attack, in which it was re-coded into two categories: 1 - Did score in the attack; 2 - Did not score in the attack. This adjustment was necessary due to the inconsistencies presented in the model with the previously stipulated categories. As independent variables we considered the effect of the reception, the attack tempo and the type of attack. For the differentiation of the type of game practiced according to the position of the attack, models were elaborated according to the effect of reception. Thus, models were created from the reception $\mathrm{A}$ and $\mathrm{B}$, since there were no attacks from position 6 after the reception C. In this context, the models presented as a dependent variable the position of the attack, that is, position 1 or 6 , and as independent variables the attack tempo, the type of attack and the effect of the attack. In the treatment of the data the significance level of $5 \%(p \leq 0.05)$ was adopted and the SPSS (Statistical Package for the Social Sciences) software version 20.0 for Windows was used. 


\section{RESULTS}

The descriptive results of the game's procedures are shown in Table 1 . The analysis of these results shows that most of the attacks occurred after reception A and the second attack tempo. In addition, the most recurrent type of attack was the strong diagonal attack, as well as the point of attack.
The adjusted model of the characterization of the game by the attacker of position 1 was statistically significant $\left(\chi^{2}=87.14, \mathrm{p}<0.001\right)$ and the estimates of the coefficients of the model, as well as the respective percentages of occurrence of the independent variables are found in the Table 2.

Table 1

Descriptive analysis of game procedures

\begin{tabular}{|c|c|c|c|c|c|}
\hline & & Position 1 & Position 6 & Total & $\%$ \\
\hline \multirow{3}{*}{$\begin{array}{l}\text { Effect of } \\
\text { reception }\end{array}$} & Reception A & 924 & 659 & 1583 & 53 \\
\hline & Reception B & 587 & 265 & 852 & 29 \\
\hline & Reception C & 534 & 0 & 534 & 18 \\
\hline \multirow{2}{*}{$\begin{array}{l}\text { Attack } \\
\text { tempo }\end{array}$} & $2^{\circ}$ tempo & 1511 & 924 & 2435 & 82 \\
\hline & $3^{\circ}$ tempo & 534 & 0 & 534 & 18 \\
\hline \multirow{3}{*}{$\begin{array}{l}\text { Type of } \\
\text { attack }\end{array}$} & SAP & 756 & 409 & 1165 & 39 \\
\hline & SAD & 1083 & 515 & 1598 & 54 \\
\hline & OSA & 206 & 0 & 206 & 7 \\
\hline \multirow{3}{*}{$\begin{array}{c}\text { Effect of } \\
\text { attack }\end{array}$} & Point & 1209 & 536 & 1745 & 59 \\
\hline & Continuity & 350 & 148 & 498 & 17 \\
\hline & Error & 486 & 240 & 726 & 24 \\
\hline
\end{tabular}

SAP $=$ Strong attack in parallel; SAD $=$ Strong attack in diagonal; OSA $=$ Off-speed attack

Table 2

Predictive factors of the game practiced by the attacker of the position 1

\begin{tabular}{|c|c|c|c|c|c|c|c|}
\hline \multicolumn{2}{|c|}{ Did score in the attack ${ }^{a}$} & \multirow{2}{*}{$\begin{array}{c}\mathrm{N} \\
924\end{array}$} & \multirow{2}{*}{$\begin{array}{c}\% \\
45.2\end{array}$} & \multirow{2}{*}{$\begin{array}{l}\text { Sig. } \\
.0004\end{array}$} & \multirow{2}{*}{$\begin{array}{c}\text { Odds ratio } \\
\text { adjusted }\end{array}$} & \multicolumn{2}{|c|}{$\begin{array}{l}\text { Confidence Interval:95\% } \\
\text { for odds ratio adjusted } \\
\text { Lower Limit Upper limit }\end{array}$} \\
\hline \multirow{3}{*}{ Effect of reception } & Reception A & & & & & .909 & 1.400 \\
\hline & Reception B & 587 & 28.7 & .026 & $1.315^{*}$ & 1.033 & 1.676 \\
\hline & Reception $\mathrm{C}^{\mathrm{b}}$ & 534 & 26.1 & & & & \\
\hline \multirow{2}{*}{ Attack tempo } & $2^{\circ}$ tempo & 1511 & 73.9 & 0.006 & $1.320^{*}$ & 1.081 & 1.610 \\
\hline & $3^{\circ}$ tempo $^{\mathrm{b}}$ & 534 & 26.1 & & & & \\
\hline \multirow{3}{*}{ Type of attack } & SAP & 756 & 37.0 & .00005 & $1.915^{*}$ & 1.395 & 2.629 \\
\hline & SAD & 1083 & 53.0 & .0000001 & $3.441^{*}$ & 2.523 & 4.695 \\
\hline & OSA $^{b}$ & 206 & 10.1 & & & & \\
\hline
\end{tabular}

${ }^{*}=$ Significant odds ratio adjusted. $\mathrm{p}<0.05{ }^{\mathrm{a}}{ }^{\mathrm{T}}$ The reference category of the dependent variable is: not score; ${ }^{\mathrm{b}}$ The reference category of the independent variable; SAP = Strong attack in parallel; SAD = Strong attack in diagonal; OSA = Off-speed attack

The adjusted model of the characterization of the game practiced by the attacker of position 6 was statistically significant $\left(\chi^{2}=81.41, \mathrm{p}\right.$ $<0.001)$ and the estimates of the coefficients of the model, as well as the respective percentages of occurrence of the independent variables are found in the Table 3.

The adjusted model that distinguishes the game practiced by the attackers of positions 1 and 6 after the reception A was statistically significant $\left(\chi^{2}=179.98, p<0.001\right)$ and the coefficient estimates of the model, as well as the respective percentages of occurrence of the variables are shown in Table 4.

The adjusted model that distinguishes the game practiced by the attackers of positions 1 and 6 after the reception B was statistically significant $\left(\chi^{2}=179.98, \mathrm{p}<0.001\right)$ and the coefficient estimates of the model, as well as the respective percentages of occurrence of the variables Are shown in Table 5. 
Table 3

Predictive factors of the game practiced by the attacker of position 6

\begin{tabular}{|c|c|c|c|c|c|c|c|}
\hline \multicolumn{2}{|c|}{ Did score in the attack ${ }^{a}$} & \multirow{2}{*}{$\begin{array}{c}\mathrm{N} \\
659\end{array}$} & \multirow{2}{*}{$\begin{array}{c}\% \\
71.3\end{array}$} & \multirow{2}{*}{$\begin{array}{c}\text { Sig. } \\
.0000001\end{array}$} & \multirow{2}{*}{$\begin{array}{c}\text { Odds ratio } \\
\text { adjusted }\end{array}$} & \multicolumn{2}{|c|}{$\begin{array}{l}\text { Confidence interval: } 95 \% \\
\text { for odds ratio adjusted } \\
\text { Lower limit Upper limit }\end{array}$} \\
\hline \multirow{2}{*}{ Effect of reception } & Reception A & & & & & 2.517 & 4.590 \\
\hline & Reception $\mathrm{B}^{\mathrm{b}}$ & 265 & 28.7 & & & & \\
\hline Attack tempo & $2^{\circ}$ tempo & 924 & 100.0 & & & & \\
\hline \multirow{2}{*}{ Type of attack } & SAP & 409 & 44.3 & .002 & $1.536^{*}$ & 1.164 & 2.027 \\
\hline & $\mathrm{SAD}^{\mathrm{b}}$ & 515 & 55.7 & & & & \\
\hline
\end{tabular}

${ }^{*}=$ Significant odds ratio adjusted. $\mathrm{p}<0.05$; $^{\mathrm{a}}$ The reference category of the dependent variable is: not score; ${ }^{\mathrm{b}}$ The reference category of the independent variable; SAP = Strong attack in parallel; SAD = Strong attack in diagonal; OSA = Off-speed attack

Table 4

Predictive factors that differentiate the game practiced by the attackers of positions 1 and 6 after the reception $A$

\begin{tabular}{|c|c|c|c|c|c|c|c|}
\hline \multicolumn{2}{|c|}{ Position $1^{a}$} & \multirow{2}{*}{$\begin{array}{c}\mathrm{N} \\
1583\end{array}$} & \multirow{2}{*}{$\begin{array}{c}\% \\
100\end{array}$} & \multirow[t]{2}{*}{ Sig. } & \multirow[t]{2}{*}{$\begin{array}{l}\text { Odds ratio } \\
\text { adjusted }\end{array}$} & \multicolumn{2}{|c|}{$\begin{array}{l}\text { Confidence interval: } 95 \% \\
\text { for odds ratio adjusted } \\
\text { Lower limit Lower limit }\end{array}$} \\
\hline Attack tempo & $2^{\circ}$ tempo & & & & & & \\
\hline \multirow{3}{*}{ Type of attack } & SAP & 678 & 42.8 & .0000001 & $2.354^{*}$ & 1.772 & 3.127 \\
\hline & SAD & 596 & 37.7 & .0000001 & $6.743^{*}$ & 4.957 & 9.173 \\
\hline & OSA $^{b}$ & 309 & 19.5 & & & & \\
\hline \multirow{3}{*}{ Effect of attack } & Point & 1009 & 63.7 & .082 & .794 & .613 & 1.030 \\
\hline & Continuity & 214 & 13.5 & .029 & $1.516^{*}$ & 1.043 & 2.204 \\
\hline & Error $^{\mathrm{b}}$ & 360 & 22.7 & & & & \\
\hline
\end{tabular}

${ }^{*}=$ Significant odds ratio adjusted. $\mathrm{p}<0.05 ;^{\mathrm{a}}$ The reference category of the dependent variable is: position 6 ; $^{\mathrm{b}}$ The reference category of the independent variable; SAP $=$ Strong attack in parallel; SAD = Strong attack in diagonal; OSA = Off-speed attack

Table 5

Predictive factors that differentiate the game practiced by the attackers of positions 1 and 6 after the reception $B$

\begin{tabular}{|c|c|c|c|c|c|c|c|}
\hline \multicolumn{2}{|c|}{ Position $1^{a}$} & \multirow{2}{*}{$\begin{array}{c}\mathrm{N} \\
851\end{array}$} & \multirow{2}{*}{$\begin{array}{c}\% \\
100\end{array}$} & \multirow[t]{2}{*}{ Sig. } & \multirow[t]{2}{*}{$\begin{array}{l}\text { Odds ratio } \\
\text { adjusted }\end{array}$} & \multicolumn{2}{|c|}{$\begin{array}{l}\text { Confidence interval } 95 \% \\
\text { for odds ratio adjusted }\end{array}$} \\
\hline Attack temno & 20 temno & & & & & & \\
\hline \multirow{3}{*}{ Type of attack } & SAP & 316 & 37.1 & .0000001 & $3.780^{*}$ & 2.471 & 5.783 \\
\hline & SAD & 390 & 45.8 & .0000001 & $6.353^{*}$ & 4.138 & 9.755 \\
\hline & $\mathrm{OSP}^{\mathrm{b}}$ & 145 & 17.0 & & & & \\
\hline \multirow{3}{*}{ Effect of attack } & Point & 447 & 52.5 & .0000001 & $2.032^{*}$ & 1.417 & 2.913 \\
\hline & Continuity & 159 & 18.7 & .172 & .741 & .482 & 1.139 \\
\hline & Error $^{\mathrm{b}}$ & 245 & 28.8 & & & & \\
\hline
\end{tabular}

${ }^{*}=$ Significant odds ratio adjusted. $\mathrm{p}<0.05$; $^{\text {a }}$ The reference category of the dependent variable is: position 6 ; $^{\mathrm{b}}$ The reference category of the independent variable; SAP $=$ Strong attack in parallel; SAD $=$ Strong attack in diagonal; OSA $=$ Off-speed attack

\section{DISCUSSION}

The present study aimed to identify the predictive factors of the attacks performed from positions 1 and 6 , according to the effect of reception in high level male Brazilian volleyball, as well as to find the predictive factors that differentiate the game practiced from these positions. The descriptive data showed that most of the attacks of positions 1 and 6 occurred after the reception of high effect and the second attack tempo. In addition, it was observed that the most used types of attacks were the strong ones and the most recurrent effect of the attack was the point. Although no articles were found in the literature that specifically analysed the attacks performed from positions 1 and 6, it was observed that the results found are in agreement with the literature, since high effect of receptions are more recurrent and lead to the conquest of the point, while low effect of receptions generate attack error (Costa et al., 2011) or continuity of the game (Castro, Souza, \& Mesquita, 2011). Moreover, the strong attack is claimed for the conquest of the point, 
evidencing the need to overlap with the opposing defensive system (Castro et al., 2011; Costa, Afonso, Barbosa, Coutinho, \& Mesquita, 2014).

The analysis of the predictive factors of the game practiced by the attacker from position 1 showed that this attacker has more chance of scoring after an excellent $(\mathrm{ORA}=1.48)$ and moderate reception effect $(\mathrm{ORA}=1.31$ ), second attack tempo (ORA $=1.32)$, strong attack in the parallel (ORA $=1.91)$ and diagonal (ORA = 3.44). The results corroborate to the preceding findings, since the effect of the previous actions influence the subsequent actions (Eom \& Schutz, 1992). In this perspective, receptions with high effect allow the use of faster attack tempos (Asterios et al., 2009), reduce the defensive organization (Costa et al., 2011) and, consequently, predict the achievement of the point (Nikos \& Elissavet, 2011; Peña, Rodríguez-Guerra, \& Serra, 2013). In this context, Silva et al. (2016b) have shown that the success in attack is related to the use of attackers in positions 1 and 6 , especially when the lifter is in positions 2, 3 and 4. In addition, it was noticed that the attacker of position 1 attacked at the $2^{\text {nd }}$ and $3^{\text {rd }}$ tempo, allowing to infer that even in receptions of moderate or low effect it was possible to perform the setting with moderate speed, as the first attack tempo is associated to high effect receptions, as it demand high precision from the setter (Afonso, Mesquita, \& Palao, 2005; Laios \& Moustakidis, 2011).

The analysis of the predictive factors of the game practiced by the attacker of position 6 showed that this attacker has more chance to score after the reception of high effect (ORA = 3.39) and the strong attack in the parallel (ORA $=1.53$ ). These results showed that the game performed at the position 6 was effective under optimal conditions of distribution, which can be attributed to attack combinations that rely on high effect reception to increase the uncertainty of the opposing team, as well as to increase the chances of success in attacking. Thus, according to Silva et al. (2016b), an effective attack combination involving position 6 is the pipe ball, where the attacker of position 6 performs the attack practically in the same space as the attacker of position 3, however in different attack tempo. Nevertheless, for this type of offensive to be effective, high effect reception is required (Silva et al., 2013), since there is a dependence of the attacker of position 3 and this shows association with high effect receptions and $1^{\text {st }}$ attack tempo (Costa et al., 2016b).

The analysis of the predictive factors of the difference of the game practiced by the attackers of positions 1 and 6 after the receptions of high effect, showed that the strong attacks of position 1 are more likely to occur in the parallel and diagonal (ORA $=2.35$ and 6.74, respectively), as well as the occurrence of continuity (ORA $=1.51$ ). Thus, according to the results found, it is possible to infer that in high-effect receptions there is an underutilization of the back-row attacks, mainly from the attacks of position 6 , as pointed out by Costa et al. (2016a), making possible the defensive system to anticipate the settings made for position 1, giving greater continuity of the game. On the other hand, the less attacks from position 6 occurs, more unpredictable they become being mostly used in a move combined with the middle-hitter, the pipe, as pointed out by Silva et al. (2016), leading the conquest of the point of attack.

The analysis of the predictive factors of the difference of the game practiced by the attackers of the positions 1 and 6 after the receptions of moderate effect showed that the strong attacks of the position 1 are more likely to occur in the parallel and diagonal (ORA $=3.78$ and 6.35, respectively), leading to the point of attack (ORA $=2.03)$. In this context, it is noticed that when the effect of the reception does not allow the use of all the attackers, being that this type of reception usually does not allow the attack of the middle-hitter, the attacker of the position 1 is effective in the conquest of the point by strong attacks. In this bias, Afonso et al. (2012) point out that in high-level men's volleyball, the opposite hitter, responsible for the attacks in positions 1 and 2, is increasingly requested in the actions of attack, a factor that can be justified by the effectiveness obtained in the offensive actions by this attacker. Besides, with the knowledge that the middle-hitter has 
limitations to incorporate the offensive system upon receiving moderate effect, the opposite hitter becomes an effective option for the attack. Another relevant factor in this context is the high request of the attacker of position 4 (Silva et al., 2013, 2014a, 2016b) promoting a tendency of anticipation of the block for this attacker, letting the attacks made by the opposite hitter to occur against a defensive system less structured when compared to the attacks of position 4 .

As limitation, we would like to highlight the fact that this study analysed the attack of professionals' male Brazilian volleyball players and perhaps the results and discussion achieved may not be extrapolated for other levels of volleyball players or to female players. Besides, technical/tactical quality of the attackers, the quality of the opponent and the difference between the teams are factors that may influence the decision of the attack movement, however these factor were not evaluated in the present study. Moreover, we recommend future investigations aiming to compare the present results to other from national tournament and national selections.

\section{CONCLUSION}

Based on data found it can be concluded that, although most of the attacks of positions 1 and 6 occurred after the reception of high effect, the reception of excellent and moderate effect showed predictive power in the achievement of the point by the attacker of position 1, suggesting that after the receptions that do or do not allow the organized attack with all the options, it becomes important to use the backrow attackers to increase the uncertainty on the opposing team and the chances to score. It is still possible to infer that even in high effect receptions there is an underutilization of backrow attackers, mainly from position 6 .

\section{Acknowledgments:}

Nothing to declare

\section{Conflict of interests:}

Nothing to declare.

\section{Funding:}

Nothing to declare.

\section{REFERENCES}

Afonso, J., Esteves, F., Araújo, R., Thomas, L., \& Mesquita, I. (2012). Tactical determinants of setting zone in elite men's volleyball. Journal of Sports Science \& Medicine, 11 (1), 64-70.

Afonso, J., Mesquita, I., Marcelino, J., \& Silva, J. (2010). Analysis of the setter's tactical action in high-performance women's volleyball. Kinesiology, 42 (1), 82-89.

Afonso, J., Mesquita, I., \& Palao, J. M. (2005). Relationship between the use of commit-block and the numbers of blockers and block effectiveness. International Journal of Performance Analysis in Sport, 5(2), 36-45.

Asterios, P., Kostantinos, C., Athanasios, M., \& Dimitrios, K. (2009). Comparison of technical skills effectiveness of men's National Volleyball teams. International Journal of Performance Analysis in Sport, 9(1), 1-7.

Castro, J., Souza, A., \& Mesquita, I. (2011). Attack efficacy in volleyball: elite male teams. Perceptual and Motor Skills, 113(2), 395-408. doi: 10.2466/05.25.PMS.113.5.395-408.

Costa, G. C. T., Ferreira, N., Junqueira, G., Afonso, J., \& Mesquita, I. (2011). Determinants of attack tactics in youth male elite volleyball. International Journal of Performance Analysis in Sport, 11(1), 96104.

Costa, G. C. T., Afonso, J., Barbosa, R. V., Coutinho, P., \& Mesquita, I. (2014). Predictors of attack efficacy and attack type in high-level Brazilian women's volleyball. Kinesiology, 46(2), 242-248.

Costa, G. C. T., Barbosa, R. V., Freire A. B., Matias, C. J. A. S., \& Greco, P. J. (2014). Analysis of the structures of side-out with the outcome set in women's volleyball. Motricidade, 10(3), 40-49. doi: 10.6063/motricidade.10(3).2899.

Costa, G. C. T., Ceccato, J. S., Oliveira, A. S., Evangelista, B. F. B., Castro, H. O., \& Ugrinowitsch, H. (2016b). Men's high level volleyball: association between game actions on the side-out. Journal of Physical Education, 27(1), 1-15. doi: 10.4025/jphyseduc.v27i1.2152.

Costa, G. C. T., Maia, M. P., Campos, M. H., \& Ugrinowitsch, H. (2016a). Offensive structuring in men's high-level volleyball: analysis of the attack zone. Brazilian Journal of Kinanthropometry and Human Performance, 18(5), 616-619. doi: 10.5007/1980-0037.2016v18n5p611.

Drikos, S., \& Vagenas, G. (2011). Multivariate assessment of selected performance indicators in relation to the type and result of a typical set in men's elite volleyball. International Journal of Performance Analysis in Sport, 11(1), 85-95.

Eom, H. J., \& Schutz, R. W. (1992). Transition play in team performance of volleyball: A log linear analysis. Research Quarterly Exercise Sport, 63(3), 
261-269.

10.1080/02701367.1992.10608741

doi:

Fleiss, J. L., Levin, B., \& Paik, M. C. (2003). Statistical methods for rates and proportions. WileyInterscience.

Fernandez-Navarro, J., Fradua, L., Zubillaga, A., Ford, P., \& McRobert, A. (2016): Attacking and defensive styles of play in soccer: analysis of Spanish and English elite teams. Journal of Sports Sciences, 34(24), 2195-2204. doi: 10.1080/02640414.2016.1169309.

Gómez, M., Silva, R., Lorenzo, A., Kreivyte, R., \& Sampaio, J. (2016). Exploring the effects of substituting basketball players in high-level teams. Journal of Sports Sciences, 35(3), 247-254. doi: 10.1080/02640414.2016.1161217.

João, P. V., \& Pires, P. M. (2015). Effectiveness of Side-Out in the male senior volleyball according intervention player. Motricidade, 11(4), 142-150. doi: $10.6063 /$ motricidade.6302.

Laios, A., \& Moustakidis A. (2011). The setting pass and performance indices in Volleyball. International Journal of Performance Analysis in Sport, 11(1), 34-39.

Maia, N., \& Mesquita I. (2006). Estudo das zonas e eficácia da recepção em função do jogador recebedor no voleibol sênior feminino. [Studying of zones and reception efficiency in function of the senior female volleyball digger]. Revista Brasileira de Educação Física e Esporte, 20(4), 257 270. doi: 10.1590/S1807-55092006000400004.

Marelic, N., Zufar, G., \& Omrcen, D. (1998). Influence of some situation-related parameters on the score in volleyball. Kinesiology, 30(2), 5565.

Marcelino, R., Mesquita, I., \& Sampaio, J. (2011). Effects of effect of opposition and match status on technical and tactical performances in elite volleyball. Journal of Sports Science, 29(7), 733741. doi: 10.1080/02640414.2011.552516.

Mesquita, I., Palao, J., Marcelino, R., \& Afonso, J. (2013). Performance analysis in indoor volleyball and beach volleyball. In T. McGarry, P. O’Donoghue, \& A. Sampaio (Eds.), Routledge Handbook of Sports Performance Analysis (pp. 436463). Oxon: Routledge, Taylor \& Francis Group.

Millán-Sanchez, A., Rábago, J. C. M., Hernández, M. A., Marzo, P. F., \& Ureña, A. (2015). Participation in terminal actions according to the role of the player and his location on the court in top-level men's volleyball. International Journal of Performance Analysis in Sport, 15(2), 608-19.

Nikos, B., \& Elissavet, N. M. (2011). Setter's performance and attack tempo as determinants of attack efficacy in Olympic-level male volleyball teams. International Journal of Performance Analysis in Sport, 11 (3), 535-544.

Palao, J. M., Santos, J. A., \& Ureña, A. (2007). Effect of the manner of spike execution on spike performance in volleyball. International Journal of Performance Analysis in Sport, 7(2), 126-38.

Peña, J., Rodríguez-Guerra, J., \& Serra, N. (2013). Which skills and factors better predict winning and losing in high-level men's volleyball? Journal of Strength and Conditioning Research, 27(9), 24872493. doi: 10.1519/JSC.0b013e31827f4dbe.

Rocha, C. M., \& Barbanti, V. J. (2006). An analysis of the confrontations in the first sequence of game actions in Brazilian volleyball. Journal of Human Movement Studies, 50(4), 259-272.

Silva, M., Lacerda, D., \& João, P. V. (2014a). GameRelated volleyball skills that influence victory. Journal of Human Kinects, 41(1), 173-179. doi: 10.2478/hukin-2014-0045.

Silva, M., Marcelino, R., Lacerda, D., \& João, P. V. (2016a). Match analysis in volleyball: a systematic review. Montenegrin Journal of Sports Science Medicine, 5(1), 35-46.

Silva, M. Sattler, T., Lacerda, D., \& João, P. V. (2016b). Match analysis according to the performance of team rotations in volleyball. International Journal of Performance Analysis in Sport, 16(3), 1076-1086.

Silva, M., Lacerda, D., \& João, P. V. (2013). Match analysis of discrimination skills according to the setter attack zone position in high level volleyball. International Journal of Performance Analysis in Sport, 13 (2), 452-460.

Silva, M., Lacerda, D., \& João, P. V. (2014a). Match analysis of discrimination skills according to the setter defence zone position in high level volleyball. International Journal of Performance Analysis in Sport, 14(2), 463-472.

Tabachnick, B., \& Fidell, L. (2013). Using multivariate statistics (6th. Ed.). Boston: Allyn \& Bacon.

Zetou, E., Tsigilis, N., Moustakidis, A., \& Komninakidou, A. (2007). Does effectiveness of skill in complex I predict win in men`s Olympic volleyball games? Journal of Quantitative Analysis in Sports, 3(4), 1-11. doi: 10.2202/15590410.1076. 